\title{
The Incompatibility of End-User Learning Styles and the Current ERP Training Approach
}

\author{
Monta Chayakonvikom, Parin Fuangvut, and Nantika Prinyapol
}

\begin{abstract}
ERP education and training is the critical success factor in an ERP implementation project but the ineffectiveness of current ERP training is still reported. Ineffective ERP education and training lead to user resistance towards an ERP system which makes the organization unable to achieve the long term benefits of ERP implementation. The ERP system was developed based on a universal culture and applied equally to all situations without consideration of the differences between ERP design and the organization in reality, which may be problematic. Thereby, the aim of this article is to investigate whether the current ERP training approach accommodates the variety of end-user learning styles. To achieve this objective, a pilot study was conducted to measure the training outcomes of the current ERP training delivered to various groups with different end-user learning styles. In-depth interviews were conducted with 30 end-users who have experience in ERP training during the period of implementation phase in a Thai context. The pilot study result supported the assumption by showing the incompatibility of end-user learning styles and the current ERP training approach, which affects the ERP training outcome.
\end{abstract}

Index Terms-Cross cultural, ERP training, individual learning style, training outcomes.

\section{INTRODUCTION}

An Enterprise Resource Planning (ERP) system is a powerful information system that has been used since the 1960s. The main characteristic of an ERP system is the integration of all important activities in the business process of the organization into a computer and data-base system which serves the organization's needs in all business units and facilitates the sharing of information including communication between each business unit in an organization ERP implementation solves the complex problem of maintaining the variety of the legacy system and also improves the business process efficiently in management operations [1]. Although an ERP system provides a lot of benefits, a high number of ERP implementation failures are still reported. Most ERP projects were failures [2] and half of ERP implementation failures were over-budget and postponed go-live project schedules [3], because both the organization and users lacked readiness. A quarter of ERP projects faced user resistance [4] even though the ERP project was successfully implemented from a technical perspective. Consequently, various reasons for user resistance have been

Manuscript received September 20, 2014; revised December 29, 2014.

Monta Chayakonvikom and Nantika Prinyapol are with the Dhurakij Pundit University, Bangkok 10210, Thailand (e-mail: Monta_Chayakonvikom@Yahoo.com, Nantika.pri@dpu.ac.th).

Parin Fuangvut is with the Sripratum University, Bangkok 10900, Thailand (e-mail: Parin.fu@spu.ac.th). studied by many academics and researchers. Importantly, the lack of ERP education and training were the most cited cause of user resistance. Reference [4] found that inadequate ERP education and training are the most significant reasons for user resistance in ERP projects.

End-user training was usually arranged during the project implementation phase. However, it did not guarantee user satisfaction [5]. The current ERP training can deliver only 25 percent of ERP knowledge to end-users [6], which is not sufficient to encourage end-users to use an ERP system by themselves. Therefore, additional training and support is required [7]. For this reason, many academics and researchers, References [8]-[10] conducted research to improve the quality of ERP training, which is considered as a major area for the ERP researcher domain. Moreover, many factors have been investigated to improve ERP training efficiently, but a lack of attention has been given to cross cultural issues. This research argues that ERP cross cultural study should not be limited only to the business process, but the training approach designed by ERP vendors should also be investigated. Prior researchers suggested that future research should study the compatibility between ERP design and organizations in reality as to whether it is appropriate or fails to match the organization. The adoption and implementation of an ERP system in different organizational contexts should be investigated because these factors might be the cause of problems [11].

Thus this article aims to investigate whether the current ERP training approach is compatible with the variety of end-user learning styles. The contribution of this research not only fulfills the knowledge gap in the ERP cross cultural area, but can also encourage ERP venders to be careful when designing an ERP training approach that should accommodate the variety of end-user learning styles. These can facilitate the improvement of ERP training in achieving knowledge transfer and reduce user resistance to the new system. The success of improving end-user training not only enhances the effective performance of tasks, but also helps organizations to reduce additional training cost and maintenance cost for providing extra support to end users when using the new system.

\section{LITERATURE REVIEW}

\section{A. The Current ERP Training Approach}

The current ERP training uses the ERP methodology-training approach, which is embedded in ERP implementation methodology. Most ERP consultants use implementation methods that were developed by ERP vendors, including the training approach, because the method 
can make sure no step is forgotten and the process can be repeated reliably [12]. An example of ERP implementation methodology in Fig. 1 is accelerated SAP (ASAP) which was introduced by SAP, the leader in the ERP market. The ASAP roadmap comprises five phases, which are project preparation, business blueprint, realization, final preparation and go-live and support. These are also similar to other vendors' implementation methodologies such as Microsoft, Oracle and Baan. Most of these methodologies provide end-user training at the end of the implementation process before starting to operate the new system in the go-live phase, and take one or two weeks of the whole project, which is around twelve months [13].

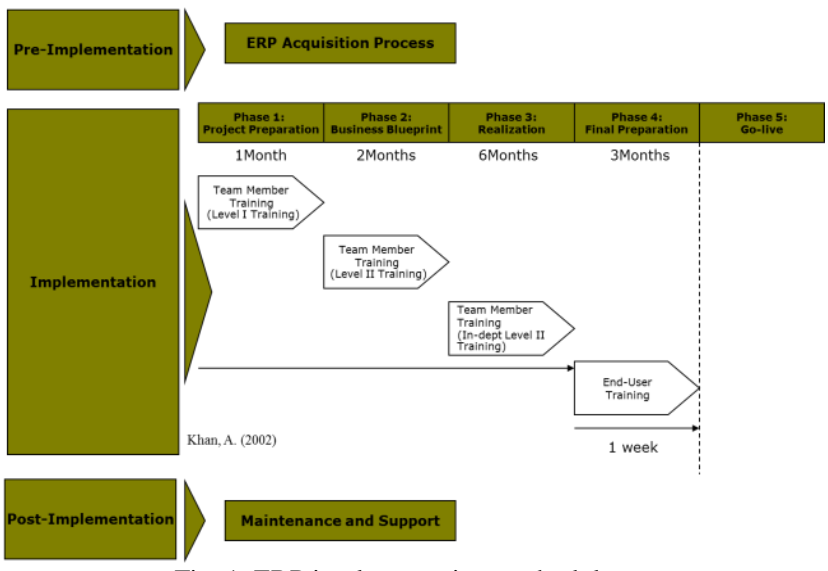

Fig. 1. ERP implementation methodology.

The characteristics of the ERP methodology-training approach is, firstly, an instructor lead classroom. The second is vender design which delivers training that tends to lack depth and business relevance in terms of content. Third, there is also poor time and quality management because of the conflict between project time and cost constraints. Companies have concerns about the training approaches provided by vendors that offer few options including a training plan, a training technique, training materials and others. Usually vendors offer a training plan according to the implementation methodology. Other kinds of expertise training, for example, extra requirements for training, are usually expensive and are not included in the training plan during ERP implementation [14]. Most end-users are not satisfied with this training approach because this approach fails to make users able to use the new system by themselves and consequently, they still need support from the support team. In many cases, it is necessary to refresh training and coaching with one-to-one mentoring after the go-live project.

\section{B. Individual Learning Style}

Reference [15] defined learning style as "the generalized differences in learning orientation based on the degree to which people emphasize the four modes of the learning process". Instructors should not assume that all learners have the same learning style or one teaching approach will be perfect for all students because the mismatch of training design and learning style is the cause of failure in the knowledge transfer process. Therefore, the primary thing academics should do is to examine their students' specific learning preferences and apply appropriate teaching strategies to maximize their learning outcomes [16]. Accordingly, the popular learning style inventory (LSI) was proposed by Kolb, and is widely used to classify individual learning styles.

Reference [17] proposed a learning style inventory based on four learning modes. First, Concrete Experience (CE) or learning from feeling; second, Reflective Observation (RO) or learning by watching and listening; third, Abstract Conceptualization (AC) or learning by thinking and, fourth, Active Experimentation (AE) or learning by doing. An individual learning style is based on these four learning modes. Consequently, learning modes can be categorized into four learning styles as follows:

- Converging learning style: obtaining knowledge by thinking or analysis and then practically applying the new ideas or concepts (learning by thinking and doing).

- Diverging learning style: acquiring knowledge based on instinct. The strength of this learning style is the imaginative ability to integrate information into meaningful understanding (learning by feeling and watching).

- Assimilator learning style: learning from abstract conceptualization by thinking, analyzing, planning and then reflecting on observations. However, this learning style is not compatible with practical applications (learning by watching and thinking).

- Accommodator learning style: learning based on applying other experience to complete projects and be-coming fulfilled in a new experience. However, this learning style lacks analytical abilities (learning by doing and feeling).

The student learning style should be considered when developing a learning program because the mismatch between teaching design and learning style can affect the learning outcome. Accordingly, academics should provide appropriate teaching strategies to match the variety of learning styles in order to maximize learning outcomes.

\section{Training Outcome}

As previously mentioned, the incompatibility of training and individual learning styles also affects the training outcome. Therefore, training outcome evaluation is an important process for gathering data and feedback to regulate training efficiently, so training can be reviewed and developed in a way that helps the organization to achieve its objective. The popular approach to evaluate training outcomes in an organization is Kirkpatrick's framework. A single dimension of measurement for training outcomes is not sufficient to reflect the complexity of a training program and can lead to a biased conclusion [18]. Therefore, Kirkpatrick's framework is appropriate to use because this framework provides evaluation of training outcomes on four levels as follows:

- Level 1: Reaction: this level provides the opportunity for participants to evaluate various aspects of training including satisfaction, opinion or the important of training.

- Level 2: Learning: this level measures the amount of information that learners have acquired during the course. This level relies on evaluation data provided by trainers to enhance the knowledge and skills of the learner.

- Level 3: Behavior: this level measures learner's ability to apply the skills and knowledge gained from training in actual use. Level three is widely used to evaluate training 
at this time, especially in computer based performance testing because it is clear whether a learner can apply knowledge in actual use.

- Level 4: Results: this level measures the impacts of training on organization goals and objectives including cost reduction, quality and quantity improvement.

\section{Learning Styles and Training Design in ERP Context}

The diversity of end-user learning styles is important when the question of improving training efficiently arises. Education researchers have searched for a theory to explain the relationship between a wide range of individual learning styles and teaching designs. An appropriate teaching design and individual learning style can enhance the performance of learning outcomes [19]-[21]. As well as Information System (IS) research, the impact of individual learning styles are important factors for the success of computer system training [22]. Reference [23] mentioned that individual learning styles and training have significant impacts on end-user task performance, based on the investigation of the training methods which were used in ERP implementation to support the training activities. Consequently, the appropriate matching of learning styles and training methodology yielded more successful training outcomes, generated greater satisfaction and yielded higher levels of computer use [24], [25].

The ERP system was designed based on a universal culture and has been applied equally to all situations. Most ERP packages originated from the West and Europe and seem to reflect Western and European culture [26]. However, the training strategies are applied equally in different contexts. The current ERP training approach does not vary training instruction for different learning styles, which is problematic [27], for example in Asia, where there are profound differences in culture including learning patterns [28]. Operational staffs in Asian have more limited skills and professional education which means the operations staffs lack the capability to face complex solutions like an ERP system. Learning how to use an ERP system requires self-learning to understand and master the system, but most employees in Asia do not make this effort because the learning system is different [29]. For this reason, the current ERP training approach is designed without consideration of the different end-user learning styles and may be a cause of the ineffectiveness of the current ERP training approach. This needs to be investigated further.

\section{MethodOLOGY}

The richness of training outcomes in the current ERP training approach accommodates the variety of end-user learning styles. A qualitative research approach in gathering data was adopted in this study. The use of a qualitative approach helps to provide readers with real-life examples of what is being conveyed. Interviews are often employed as an effective tool to understand people's experience and to suggest useful explanations or interpretations about the collected qualitative data [30]. Therefore, in-depth interviews of individuals are appropriate for the research purpose of exploring the training outcomes with the variety of end-users learning styles according to the four levels of Kirkpatrick's framework. Furthermore in this research, the questionnaire is also applied as an instrument for collecting data to classify end-user learning styles and is based on Kolb's learning style inventory, including demographic data.

The population is end-users who have experience in ERP training during the period of project implementation. End-users who work closely with an ERP system are the ones who are best placed to provide rich information on the current ERP training. The samples were selected from a list of ERP customer site references by employing a purposive sampling strategy. The list of ERP customer site references were acquired from ERP consulting companies in Thailand (non-public sources). The data qualities were verified by telephone including duplicate data elimination. To achieve the research objective, a pilot study was conducted to test the research assumptions. Thirty end-users from six companies with the variety of ERP platforms for example SAP R/3, SAP Business One and Microsoft Dynamic participated in this study. The content analysis involved reviewing the training outcomes of the current ERP training delivered to various groups of learning styles to locate commonly occurring themes that are representative of academic adjustment issues.

\section{RESUlT}

This section explains the training outcome evaluation of the current ERP training delivered to various groups with different end-user learning styles. The empirical data of end-user learning styles classification in Fig. 2 reveals the accommodating learning style to be the most used learning style based on the sample of the pilot test; the converging learning style was the second largest; the third was an assimilating learning style and the diverging learning style was the smallest group of end-user learning styles.

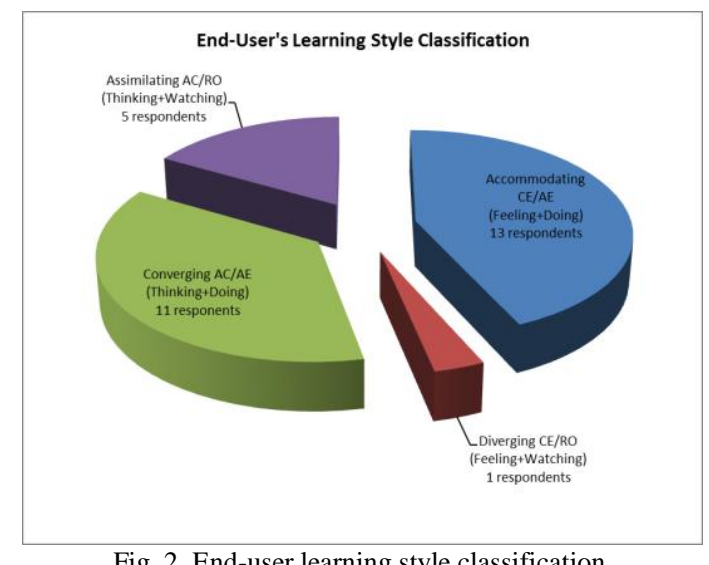

Fig. 2. End-user learning style classification.

The training outcome evaluation of the current ERP training delivered to various groups with different end-user learning styles is shown below:

Level 1: To measure end-user's attitudes towards the current ERP training. The result indicated that mostly end-users of all learning styles were dissatisfied with the current ERP training in four areas: training method, training content, training and user manual, and training time allocation.

- Training Method: End-users were dissatisfied with the 
training method because of poor organization of lectures and practice during the training course. The whole training course was focused on lecturing but failed to give sufficient time for end-users to practice and get familiar with the new system. This dissatisfaction was classified as an accommodating learning style, where students learn according to concrete experience and active experimentation (learning by feeling and doing). End-users in this group also suggest the training method should pay more attention to practice or workshop by applying real work cases, scenarios or case studies which match the specific organization's requirements in practice or in a workshop as much as possible, rather than teaching how to complete transactions via lecturing using slides. Another area of dissatisfaction with the current ERP training method was "Train-the-Trainer". All groups of end-user learning styles were more satisfied to be trained directly by ERP consultants rather than key-users (a key-user is the person in an organization who has been selected to be the key person, who involves the whole implementation process including being training directly by an ERP consultant. Key-users take responsibility to teach end-users to use the new system in an organization) The Train-the-Trainer training method was proposed by software companies and is bundled in the ERP implementation methodology and applied worldwide. Many end-users were dissatisfied to be trained by key-users because key-users lack the capability to transfer knowledge about how to use the ERP system properly. Key-users were often unable to answer end-users' questions on the business processes and the various functions of the ERP system and often lacked teaching skill. Thus most end-users preferred to be trained directly by ERP consultants rather than key-users, especially in the converging learning style group who learn according to abstract conceptualization and active experimentation (learning by thinking and doing). Users in this group learn by analyzing and asking questions to enhance their knowledge, but key-users could not provide clear answers. End-users also mentioned that several key-users were acting as messengers rather than experts to transfer knowledge by referring end-user questions to ERP consultants to find the answers. This process is inadequate. Why end-users cannot be trained directly by ERP consultants was questioned by end-users in this learning style group.

- Training Content: End-users were dissatisfied with the training content because it was not sufficient to enhance end-users' knowledge to use ERP system in real situations. Usually the training content taught only standard business processes. Other useful content for example, special cases, unusual cases or sub details, apart from the standard processes were not provided. For this reason, end-users lack the capability to handle business cases other than the standard processes by themselves. End-users in the group of converging learning style suggested that the training content should not be limited only to the parts of each end-user's responsibility but that other content is important as well. For example, the fundamentals of the ERP system, the workflow and the relationship of each module in the ERP system including the data flow diagram and the participants in each part of the data in the ERP system should be included because this content helps to enhance end-user's understanding of the overall system, who is involved in each part of data, and who are the creators and users of these data. This would not only enhance end-users' understanding, but would also increase the end-users' problem solving capabilities too. In contrast, the group of assimilating learning style did not wish to learn anything other than the parts which were related to their responsibility.

- Training Time Allocation: End-users were dissatisfied with the training time allocate. Most end-users were pressured to learn how to use an ERP system in a short time. The ERP system has a lot of details to be learned. Consequently, learning to use the ERP system in a short time period does not enhance end-users' confidence and familiarity when using the new system. The implementation plan, which was hurried, without considering the system usage capability was said to be the cause of insufficient training time allocation. Importantly, usually training courses for an ERP project are arranged at the end of the implementation process before the go-live stage. Most end-users of all learning styles recommended that training courses should not be provided in only one period before the go-live phase, but also after the go-live phase. This recommendation was made by the accommodating learning style group. After the go-live phase, end-users have usage experience of the new system so these experiences are useful for end-users to understand the training content about which end-users need to be trained, including the missing parts from the first training as well. Most end-users suggested that the training should be arranged at least two times. Firstly, before the go-live phase by explaining the basic functions of the ERP system and the standard business process. Secondly, after the go-live phase, which should include training for all business cases or applied cases, but excluding the standard business processes, to be consistent with the specific end-user requirements and the organization's business processes.

- Training and User Manual: End-users were dissatisfied with the training and user manual for various reasons i.e. understanding difficulties, including technical jargon, excessive information and the number of pages. Significantly, all end-user learning style groups preferred not to learn by reading the manual. The evidence indicates that most end-users hardly ever read the manual. The manual was not used as a tool for self-learning to increase end-user knowledge, or how to use the ERP system properly, but was used on occasions to solve problems. However, calling the support team to solve problems was the first choice rather than finding solutions in the manual by themselves. In particular, in the groups of accommodating and converging learning styles, people preferred to practice by employing trial and error in the system rather than reading the manual. On the other hand, people with an assimilating learning style preferred to develop individual manuals, which are based on the lecture notes and screen captures, with step-by-step 
explanations and less technical jargon. Thus, understanding was found to be easier for beginner users.

Level 2: In measuring levels of perception toward the current ERP training, the information indicated that most end-users of all learning styles had poor perception levels. Even for end-users with a fair perception level, it did not guarantee end-users were capable of applying knowledge gained from training in actual use. Mostly end-users thought that they completely understood and remembered all the contents of the training course, but in fact, they did not. There were problems when end-users had to cope with real situations. In such circumstances, most end-users realized that there perception level was poor. For example one respondent said "I have a good score of around 90 percent in the post ERP training exam. The good score makes me feel that I understand the whole ERP training. In fact after the go-live phase, I realized that actually I did not understand anything". The training content did not cover all business cases. All scenarios in the training were basic business processes followed step by step, which is totally different to the end-users' daily work. Another respondent said "I have something to tell you. I think ERP training sucks. I did not learn anything from this training. The training contents were a small part of all our business process. Mostly, my ERP knowledge was gained from trial and error experience including on the job training". For this reason, after the go-live phase, most end-users have to survive by themselves and restart learning how to use the ERP system by trial and error, including on the job training.

Level 3: When measuring applied knowledge behavior toward the current ERP training, most end-users of all learning styles were only quite confident and some had no confidence in using the ERP system. End-users had no idea how to use the new system at the beginning. Some end-users feared making mistakes in the system, which would affect others. The lack of training time to practicing was mentioned by most end-users as the cause of the lack of confidence, skill and familiarity to use the new system. These perceptions came from people with accommodating and converging learning styles. Importantly, some end-users who had moderate confidence to use the new system realized how to complete transactions in an ERP system. Support was also required from ERP consultants acting as coaches to enhance self-confidence.

Level 4: When measuring the training quality of the current ERP training, most end-users of all learning styles evaluated the current ERP training as 'slightly poor quality' because end-users were incapable of using the new system by themselves. Some end-users of all learning styles evaluated the current ERP training delivered as 'fair quality' because end-users became able to complete standard processes in the ERP system, but it failed to enhance end-users' knowledge to complete all of their daily jobs using the ERP system. The poor training quality not only disappointed end-users, but also affected system usage behaviors i.e. avoiding using the new system, working around it and double work (using both the existing system and the new system). For this reason, retraining was necessary and required, but providing retraining courses affect the return on investment rate because organizations had to pay extra costs for re-training.

\section{DISCUSSION AND CONCLUSION}

The findings of the empirical study identified the incompatibility of end-user learning styles with the current ERP training approach and revealed negative effects on training outcomes, regarding the four levels of Kirkpatrick's framework which were applied to evaluate the ERP training outcomes for various groups of end-user learning styles. The results indicate that the current ERP training approaches fail to transfer knowledge to end-users as to how to use an ERP system properly. Most end-users of all learning styles had poor perception levels. Even for end-users with a fair perception level, it did not guarantee end-users were capable of applying the knowledge gained from training in actual use. Most end-users were only quite confident and some had no confidence in using the ERP system. End-users had no idea how to use the system at the beginning. Some end-users feared making mistakes that would affect others in the system. Consequently, most end-users of all learning styles evaluated the current ERP training as 'slightly poor quality' because end-users were incapable of using the new system by themselves. The poor training quality not only disappointed end-users, but also affected system usage behaviors i.e. avoiding using the new system, working around it and double work (using both the existing system and the new system). For this reason, retraining was necessary and required, but providing retraining courses affected the return on investment because organizations had to pay extra costs for re-training.

Importantly, the information also indicated that mostly end-users of all learning styles were dissatisfied with the current ERP training delivered in four areas: the training method, the training content, the training and user manual, and training time allocation, which were suggested as the causes of poor training outcomes i.e. low perception levels and lack of ability to apply the knowledge gained from training in actual use. End-users identified various reasons of dissatisfaction following the individual learning style preferences. For example, end-users in the group of accommodating learning style were dissatisfied with the poor organization of lectures and practice during the training course. Most end-users preferred to be trained directly by ERP consultants rather than key-users, especially in the converging learning style and also suggested that the training content should not only be limited to the parts of each end-user's responsibility but also should include other content. The implementation plan, which was hurried, without considering the system usage behavior, was said to be the cause of insufficient training time allocation, and training courses were arranged at the end of the implementation process before the go-live stage, so end-users were pressured to learn how to use an ERP system in a short time. Most learners of all learning styles recommended that the training courses should not be provided in only one period before the go-live phase, but also after the go-live phase, especially for the accommodating learning style group. Significantly, all end-users learning style groups preferred not to learn by reading the manual. The evidence indicates that most end-users hardly ever read the manual. The manual was not used as a tool for self-learning to increase end-user knowledge, or how to use the ERP system properly, but was used on occasions to solve problems. These implications indicate that 
the current ERP training strategies fail to accommodate the variety of end-user learning styles and these incompatibilities also affect the training outcomes. Previous research in the education area has mentioned the incompatibility of teaching and how learning style impacts the effectiveness of training outcomes

The ERP systems, including training strategies, were designed based on a single, universal culture concept and have been applied in all situations, and hence does not provide varied training instruction for different learning styles. The ERP training, designed without consideration of diverse learning styles and cultures, may be the cause of the ineffectiveness of the current ERP training approach, which is consistent with previous research in the education area which found that learning style preferences were influenced by culture. For this reason, a better understanding of the cultural background and learning styles in education is required to increase the success rate of ERP training.

Consequently, to explore the concept of culture in education and to explain end-user dissatisfaction issues toward the current ERP training, it is necessary to investigate this further. This will help the researcher to characterize the impact of cultural values on the current ERP training approach. This information will be used as evidence to be considered in ERP instructional design, which should be culturally inclusive and able to accommodate various learning styles. Moreover the number of respondents in groups of assimilating and diverging learning styles is a limitation in this study, which means that more investigation is necessary.

\section{REFERENCES}

[1] P. Hawking and A. Stein, "Revisting ERP systems: Benefit realization," in Proc. the $37^{\text {th }}$ Hawaii International Conference on System Sciences, Island of Hawaii, IEEE, 2004, pp. 1-8.

[2] E. J. Umble, R. R. Haft, and M. M. Umble, "Enterprise resource planning: Implementation procedures and critical success factors," European Journal of Operational Research, vol. 146, pp. 241-257, 2003.

[3] H. Betros and C. J. Teplitz, "Managing end users resistance in ERP installations," in Proc. Production and Operations Management Society (POMS) 22 $2^{\text {nd }}$ Annual Conference, H. Correa and R. College,ed., Nevada, U.S.A., 2011, pp. 1-21.

[4] M. Z. Aslam, "User resistance in post ERP implementation stage," M.S thesis, Dept. Informatics, Lund Univ., Sweden, 2010.

[5] J. Bradley and C. C. Lee, "ERP training and user sastisfaction: A case study," International Journal of Enterprise Information Systems, vol. 3, no. 4, pp. 33-50, 2007.

[6] T. Klaus and J. E. Blanton, "User resistance determinants and the psychological contract in enterprise system implementations," Europoean Journal of Information System, vol. 19, pp. 625-636, 2010.

[7] T. Coulson, L. Olfman, C. Shayo, and C. E. T. Rohm, "ERP training strategies: conceptual training and the formation of accurate mental models," in Proc. the 2003 SIGMIS Conference on Computer Personnel Research (SIGMIS CPR'03), Philadephia, Pennsylvania, ACM, 2003, pp. 87-97.

[8] V. Heierhoff, A. A. B. Arntzen, and G. Muller, "A training model for successful implementation of enterprise resource planning," World Academy of Science, Engineering and Technology, vol. 60, pp. 505-511, 2011.

[9] M. M. Jamjoom and A. S. Al-Mudimigh, "Training evaluation: Towards an effective ES training," International Journal of Computer Science and Network Security, vol. 11, no. 1, pp. 148-152, 2011.

[10] N. Venkateswaran and D. V. Mahalakshmi, "Competitive constructs of ERP implementation in manufacturing sectors in Chennai City," $J M$ International Journal of Information Technology (JMIJIT), vol. 1, no. 1, pp. 34-40, 2011.

[11] A. A. Hawari and R. Heeks, "Explaining ERP failure in developing countries: a Jordanian case study," The Journal of Enterprise Information Management, vol. 23, no. 2, pp. 1-29, 2010.
[12] R. Catersels, E. W. Helms, and R. Batenburg, "Exploring the gap between the practical and theoretical world of erp implementations: Results of a global survey," in Proc. the International Conference on Research and Practical Issues of Enterprise Information Systems (CONFENIS), Natal, Brazil: Prezi, 2010, pp. 1-27.

[13] A. Khan, Implementing SAP with an SAP Methodology Focus, The United State of America: Writers Club Press and Imprint of iUniverse, Inc., 2002, pp. 1-172.

[14] N. A. Ismail, H. S. Jenatabadi, and N. M. Yasin, "An effective end-user knowledge concern training method in enterprise resource planning (ERP) based on critical factors (CFs) in Malaysian SMEs," International Journal of Business an Management, vol. 5, no. 7, pp. 63-76, 2010

[15] D. A. Kolb, Experiential Learning: Experience as The Source Of Learning and Development, Englewood Cliffs: Prentice Hall, 1984, pp. 20-38.

[16] T. Wang and L. Moore, "Exploring learning style preferences of Chinese postgraduate students in Australian transitional programs," International Journal of Pedagogies and Learning vol. 3, no. 2, pp. 31-41, 2007

[17] D. A. Kolb, R. E. Boyatzis, and C. Mainemelis, "Experiential learning theory: previous research and new directions," Perspectives on Thinking, Learning, and Cognitive Styles, vol. 1, pp. 227-247, 2001.

[18] R. Bates, "A critical analysis of evaluation practice: The Krikpatrick model and the principle of beneficence," Evaluation and Program Planning, vol. 27, pp. 341-347, 2004.

[19] K. Buch and S. Bartley, "Learning style and training delivery mode preference," The Journal of Workplace Learning, vol. 14, no. 1, pp. 5-10, 2002.

[20] D. Holtbrugge and A. T.Mohr, "Cultural determinants of learning style preferences," Academic of Management Learning \& Education, vol. 9, no. 4, pp. 622-637, 2010.

[21] T. S. Proitz, "Learning outcomes: what are they? who defines them? when and where are they defined?" Educational Assessment, Evaluation and Accountability, vol. 22, no. 2, pp. 119-137, 2010.

[22] S. Hsu, R. Thakur, D. J. M. Pearson, and D. L. Cosby, "An empirical study into the effect of an indiviual's learning style on end-user computer satisfaction (EUCS): Taiwan," in Proc. IRMA International Conference, M. Khosrow-Pour, ed., pp. 569-574, New Orleans, LA, USA: IDEA Group Publishing, 2004.

[23] I. Dorobat and F. Nastase, "Personalized training in Romanian SME's ERP implementation projects," Informatica Economica, vol. 14, no. 3 , pp. 116-127, 2010.

[24] M.-P. Chu and T. Nakamura, "A study of Chinese and Japanese college students' L2 learning styles," Asian Culture and History, vol. 2, no. 2, pp. 30-44, 2010.

[25] S. J. Simon, "The relationship of learning style and training method to end-user computer satisfaction and computer use: A structural equation model," Information Technology, Learning and Performance Journal, vol. 18, no. 1, pp. 41-59, 2000.

[26] C. Soh, S. S. Kien, and J. Tay-Yap, "Enterprise resource planning: cultural fits and misfits: is ERP a universal solution?" Communications of the ACM, vol. 43, no. 4, pp. 47-51, 2000.

[27] A. Shahin, S. Sadri, and R. Gazor, "Evaluating the application of learning requirements planning model in the ERP project of Esfahan Steel Company," International Journal of Business and Management, vol. 5, no. 2, pp. 33-43, 2010.

[28] K. N. Marambe, J. D. Vermunt, and H. P. A. Boshuizen, "A cross-cultural comparision of student learning patterns in higher education," Higher Education, vol. 64, no. 3, pp. 299-316, 2012.

[29] J. Rajapakse and P. B. Seddon, "Why ERP may not be suitable for organizations in developing countries in Asia," in Proc. Pacific Asia Conference on Information Systems (PACIS), pp. 1382-1388, vol. 7, Bangkok, 2005.

[30] M. D. Myers, Qualitative Research in Business \& Management, Los Angeles: SAGE Publications Ltd., 2009, pp. 1-284.

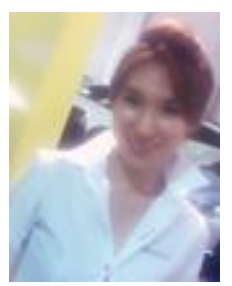

Monta Chayakonvikom is a Ph.D. candidate in the Faculty of Business Informatics, International College of Dhurakij Pundit University, Thailand. She received a bachelor of computer engineering and a master of business administrative from Sripatum University.

She has more than 10 years experience in IT and ERP consultant business with the several ERP platforms i.e. SAP R/3, SAP business one, Microsoft and oracle e-business suite. She has expertise in the scope of assists with selection, implementation, training and support for ERP systems. 


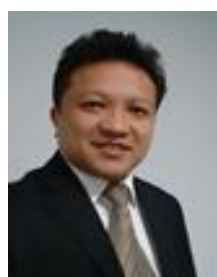

Parin Fuangvut received a doctor of philosophy (information systems) and the master of commerce (business information systems) from University of Wollongong, Australia and the bachelor of business administration (business computer) from Rangsit University, Thailand. He has been working as an information systems professional and academic for more than 17 years. His knowledge and expertise are especially focused on multiple Information systems discipline. In fact, most concrete expertise is including: IT governance, project management, business process improvement, re-engineering, enterprise information systems, enterprise portal, web site and e-business, and enterprise resource planning (ERP)

On IT professional experiences, he is currently an assistant president for Technology (CIO/CTO) at Sripatum University, Bangkok. He was also a vice president (the head of IT Governance) at CIMB Thai Bank PCL and working as a director for information systems division at the Dhurakij Pundit University. At the DPU, he was an original leader for ERP project establishment on adoption of SAP within higher education business environment and working as project manager and steering committee of 3 ERP projects: accounting \& financial, student life cycle management, and human capital management. Recently, he was invited for working as an IT consultant for establishing ICT Strategic Planning and Roadmap for PTT high school (RASA) and Higher Education Institution (RAIST) project. On the consulting experiences, he was an freelance consultant for many organizations i.e. Krungthai Panich Insurance (KPI) PCL, Siam City Insurance PCL, Aikchol Hospital PCL, Golden Cream Co.,Ltd (Café D’Oro
\& VPP Coffee), T-Thai Snack Food Co.,Ltd (Squidy Brand), General Drug House Co.,Ltd, etc. In his academic employment, he was working as a Senior Lecturer for Faculty of Information Technology at Dhurakij Pundit University (DPU), Thailand, one of the leading private universities in Thailand. Previously, he was working as a lecturer for Department of Business Administration, Faculty of Management Sciences, Prince of Songkhla University for many years.

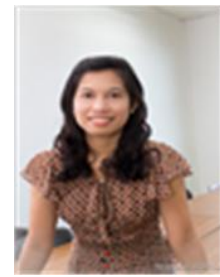

Nantika Prinyapol is a Ph.D. in University of Wollongong, Australia. She is a lecturer in the Faculty of Information Technology. Recently, she is a director of master degree in information technology for modern enterprise, Dhurakij Pundit University, Thailand. She received a bachelor of science in information technology from Assumption University and a master of science in information management from Asian Institute of Technology, Thailand.

She has worked more than 15 years at Faculty of Information Technology. She has expertise in the scope of data mining, human computer interaction, usability study, and workflow management areas. Her research is in workflow practices and web services development for business process. She has many article publications regarding information technology such as "Usability testing for an evaluation of application-learning tutorials and document-based instructor (2013)", "A dynamic nursing workflow management system: a Thailand hospital scenario (2010)", and more. 